\title{
Eurotransplant i mjesto Republike Hrvatske u njemu
}

\section{Eurotransplant and the role of Croatia in Eurotransplant}

\author{
Danko Mikulić*, Branislav Kocman
}

Klinika za kirurgiju, Klinička bolnica Merkur, Zagreb, Hrvatska

"Dopisni autor:

Dr. sc. Danko Mikulić, dr. med.

Klinika za kirurgiju, Klinička bolnica Merkur, Zajčeva 19, 10000 Zagreb

E-mail:danko.mikulic@zg.t-com.hr
Sažetak. Eurotransplant je međunarodna neprofitna organizacija koja se bavi alokacijom i prekograničnom razmjenom kadaveričnih organa za transplantaciju. Osnovana je 1967. godine i okuplja osam zemalja članica s preko 135 milijuna stanovnika, a Republika Hrvatska je članica od 2007. godine. Članstvo u Eurotransplantu za Hrvatsku je korisno zbog omogućavanja što bolje podudarnosti darivatelja i primatelja, kao i mogućnosti da se u kratkom vremenu pronađe organ u slučajevima akutnog zatajenja organa, za što je bitno veća vjerojatnost u velikoj populaciji potencijalnih darivatelja organa. Tijekom posljednjih deset do petnaest godina u Hrvatskoj je došlo do velikog porasta broja kadaveričnih darivatelja organa i broja transplantacija te ona danas zauzima jedno od vodećih mjesta u svijetu po broju darivatelja i transplantacija na milijun stanovnika, a jedan od čimbenika koji su za to zaslužni je i članstvo u Eurotransplantu. U članku je opisana organizacija, povijest i uloga Eurotransplanta $u$ alokaciji i razmjeni organa te mjesto Hrvatske u Eurotransplantu.

Ključne riječi: alokacija organa; Eurotransplant; Hrvatska; transplantacija organa

Abstract. Eurotransplant is an international non-profit organization that was founded in 1967. Its primary acitvities include allocation and cross-border exchange of organs for transplantation. Eurotransplant has eight member states and the Republic of Croatia joined in 2007. Some of the key advantages of membership in Eurotransplant's pool of potential organ donors include better matching between donors and recipients as well as the possibility to find an organ quickly for patients with acute organ failure. After joining Eurotransplant Croatia has experienced a tremendous rise in the number of cadaveric organ donors and solid organ transplants. Today, Croatia is one of the world's leaders in cadaveric organ donation and organ transplantation and Croatian membership in Eurotransplant has been one of the key factors. This review gives an outline of the structure and history of Eurotransplant and explains its role in allocation and cross-border exchange of organs. The history of relations between Croatia and Eurotransplant is described as well.

Key words: Croatia; Eurotransplant; organ transplantation; organ allocation 
Eurotransplant (ET) je neprofitna međunarodna organizacija za suradnju u alokaciji i razmjeni kadaveričnih organa za transplantaciju ${ }^{1}$. ET okuplja osam zemalja članica (Belgija, Nizozemska, Luksemburg, Njemačka, Austrija, Slovenija, Hrvatska, Mađarska). Središte Eurotransplanta je u Leidenu u Nizozemskoj. Kako je transplantacija organa postupak koji omogućuje spašavanje ili značajno poboljšanje kvalitete života pacijentima s terminalnim zatajenjem organa, Eurotransplant je osnovan kao medijator između darivateljskih i transplantacijskih centara kako bi se u što većoj mjeri ispunili svi potencijali takve suradnje, to jest kako bi se svakom primatelju pronašao što podudarniji darivatelj organa. Glavni cilj Eurotransplanta je optimalno iskorištenje dostupnih kadaveričnih organa za transplantaciju. Sustav alokacije organa temelji se na medicinskim i etičkim kriterijima, a ET upravlja složenim procesom alokacije organa i sparivanja kadaveričnih darivatelja i primatelja na listama čekanja s ciljem da se postignu najbolji mogući ishodi ${ }^{1,2}$. Pri tome je ključno načelo transparentnosti, u skladu s propisima Europske unije, etičkim načelima, kao i nacionalnim zakonodavstvima zemalja članica. Osim toga, kroz prikupljanje podataka i znanstvena istraživanja, ET aktivno sudjeluje u razvoju preporuka i politika u alokaciji organa za transplantaciju, kako bi se poboljšali procesi alokacije organa i ishodi transplantacije.

\section{ORGANIZACIJA EUROTRANSPLANTA}

Sjedište ove međunarodne neprofitne fondacije je u Leidenu u Nizozemskoj i organizacijska struktura je prilagođena nizozemskom zakonodavnom okviru. Kroz godine je ET prošao više reformi svoje strukture, a implementacija najnovije upravo je u tijeku. Eurotransplant je demokratski ustrojen i ima svoj upravni odbor, nadzorni odbor, dva savjetodavna vijeća (administrativno i medicinsko-znanstveno vijeće) i osam savjetodavnih odbora $^{1,2}$. Ovakva struktura osmišljena je tako da odgovara potrebama i željama zemalja članica, učinkovito služi darivateljskim i transplantacijskim centrima i zdravstvenim djelatnicima za dobrobit sadašnjih i budućih pacijenata.

\section{POVIJEST EUROTRANSPLANTA}

Rodonačelnik ideje o osnivanju organizacije za prekograničnu suradnju u razmjeni i alokaciji organa i svojevrsni otac Eurotransplanta bio je nizozemski imunolog Jon van Rood (1926. - 2017.)1. Radeći na transfuzijskom odjelu bolnice u Leidenu rano je razvio interes za sustav antigena tkivne kompatibilnosti (HLA). Do sredine šezdesetih godina prošlog stoljeća darivateljski organi su se alocirali primateljima ponajprije temeljem podu-

Eurotransplant je neprofitna međunarodna organizacija za suradnju u alokaciji i razmjeni kadaveričnih organa za transplantaciju. Ova organizacija ima osam zemalja članica (Belgija, Nizozemska, Luksemburg, Njemačka, Austrija, Slovenija, Hrvatska, Mađarska).

darnosti krvnih grupa. Primatelji su najčešće morali čekati dok se u njihovom transplantacijskom centru ne pojavi pogodan darivatelj. Profesor van Rood uvidio je važnost HLA sustava za ishod transplantacije bubrega, pri čemu je tkivna podudarnost darivatelja i primatelja rezultirala boljim preživljenjem presatka i primatelja. No, kako je broj HLA antigena velik, vjerojatnost pronalaska podudarnog darivatelja za pojedinog primatelja u istom centru bila je vrlo mala, stoga je van Roodu bilo jasno da bi se ta vjerojatnost povećala kad bi se organi pojedinog darivatelja ponudili većoj bazi s podacima velikog broja primatelja koji čekaju odgovarajući organ. Razmišljajući o tome kako u veću mrežu povezati velik broj darivatelja i primatelja organa, što bi povećalo šansu za veću podudarnost kod transplantacije, došao je na ideju da uspostavi mrežu europskih bolnica koje se bave transplantacijom, pa je 1967. godine nastao Eurotransplant. $U$ početku je ideju prihvatilo tek nekoliko bolnica u Nizozemskoj i Belgiji, a već u jesen 1967. godine prvi bubreg je u Leiden stigao helikopterom iz Belgije, čime je mreža budućeg Eurotransplanta praktično počela djelovati. Nakon što je uspostavljena dobrovoljna suradnja dvanaest bolnica iz Nizozemske, Belgije i Luksemburga, svi centri su u središnju bazu podataka dostavljali podatke o kandidatima na listi čekanja i kad bi se u nekom od centara pojavio darivatelj, 


\section{COUNTRIES AND NUMBER OF ACTIVETRANSPLANT CENTERS IN 2019}

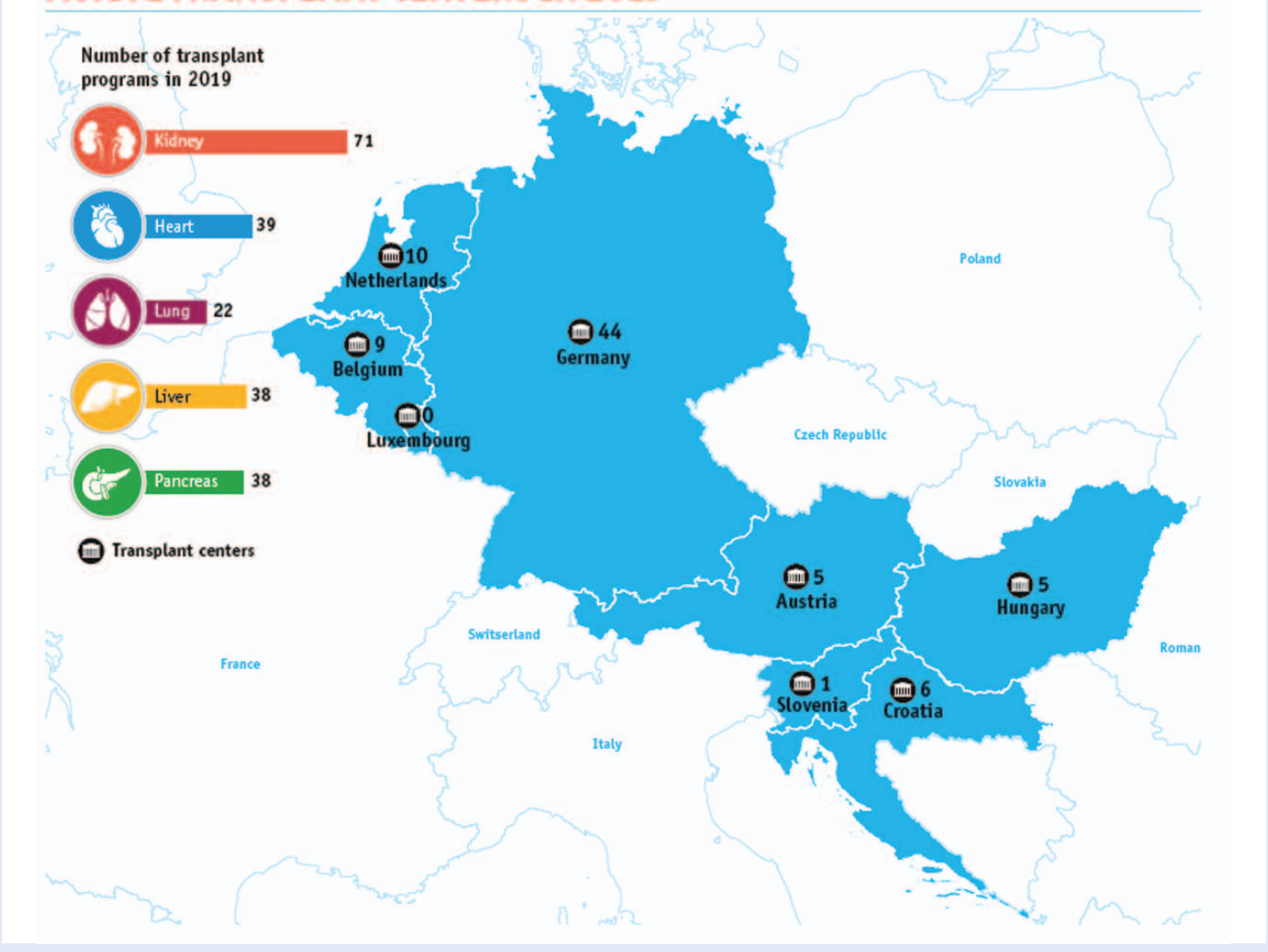

Slika 1. Zemlje članice i transplantacijski centri Eurotransplanta (izvor: www.eurotransplant.org).

organ je transplantiran najpodudarnijem primatelju bez obzira u kojem centru se nalazio na listi čekanja. Brzo se pokazalo da takva, prema primateljima orijentirana alokacija organa, daje značajno bolje rezultate u preživljenju presadaka bubrega. Eurotransplant je od samih početaka bio transnacionalna organizacija; prvim centrima članovima ubrzo se priključio niz centara iz Nizozemske, Belgije, Švicarske, Savezne Republike Njemačke, Luksemburga i Austrije. Slijedilo je razdoblje brzog rasta i već krajem 1970. bilo je aktivno 68 centara u 6 zemalja. Švicarska je kasnije napustila Eurotransplant, a priključile su se tadašnja Istočna Njemačka 1991. godine, 2000. godine Slovenija, 2007. godine Hrvatska i 2013. godine Mađarska. Danas u osam zemalja ET-a živi oko 135 milijuna stanovnika s preko 1600 darivateljskih bolnica i 77 transplantacijskih centara (slika $1)^{1,2}$. U svakom trenutku je oko 16000 pacijenata na listama čekanja, godišnje se alocira više od
7000 organa, a 10000 novih pacijenata stavlja na liste čekanja². Eurotransplant se u početku bavio samo alokacijom bubrega, a napretkom transplantacijske medicine i zahvaljujući sve većim uspjesima u transplantaciji ostalih solidnih organa, područje djelovanja se širilo i na druge organe. Tako je od kraja sedamdesetih godina prošlog stoljeća ET započeo s alokacijom jetre, od početka osamdesetih s alokacijom srca i gušterače, a u drugoj polovici osamdesetih s alokacijom pluća i tankog crijeva.

\section{EUROTRANSPLANT I ALOKACIJA ORGANA ZA TRANSPLANTACIJU}

Eurotransplant ima ključnu ulogu u alokaciji i distribuciji organa za transplantaciju. Sustav alokacije organa sačinjen je tako da bude transparentan, valjan, reproducibilan i objektivan. Budući da je vrijeme koje stoji na raspolaganju od eksplantacije do implantacije organa vrlo ograničeno (od ne- 
koliko pa do najviše 24 sata, ovisno o organu), od životne je važnosti besprijekorno funkcioniranje organizacije koja provodi i nadzire alokaciju organa. Da bi se to osiguralo, u središnjem uredu ET-a neprekidno je dežurno obučeno osoblje. Svim transplantacijskim centrima u zemljama članicama ET-a dostupna je centralna računalna baza podataka. U tu se bazu upisuju opći i medicinski podaci svakog primatelja, kao i profil potencijalnog darivatelja za tog pacijenata. Čim se negdje na području zemalja članica ET-a pojavi darivatelj, regionalni laboratorij za tipizaciju tkiva ispituje njegovu krvnu grupu i tkivne značajke. Svi relevantni podaci o darivatelju i njegovim organima prenose se u bazu podataka pri ET-u. Nakon toga se u ET-u temeljem složenog računalnog algoritma koji u obzir uzima medicinske i etičke kriterije radi lista podudarnosti ili sparivanja darivatelja i primatelja (match list) za svaki organ. Ključna načela pri sparivanju organa i primatelja su očekivani ishod i hitnost stanja primatelja. Osim toga, u obzir se uzimaju nacionalna ravnoteža organa (nastoji se postići ravnoteža u razmjeni organa između pojedinih zemalja članica), kao i vrijeme čekanja pojedinog primatelja na organ. Organi se nude za primatelje prema redoslijedu na listi sparivanja, o čemu ured ET-a obavještava transplantacijske koordinatore i liječnike u transplantacijskom centru. Ako liječnici u transplantacijskom centru prihvate organ, preko ET-a se uspostavlja kontakt između eksplantacijskog i transplantacijskog centra, određuje se vrijeme eksplantacije i dogovara se transport organa od darivateljskog do transplantacijskog centra. Danas se preko 20 \% kadaveričnih organa u zemljama Eurotransplanta razmjenjuje preko granice, to jest, transplantira se u centrima koji su izvan zemlje darivatelja ${ }^{1,2}$.

Većinu organa koji se razmjenjuju preko nacionalnih granica čine bubrezi i to prvenstveno zbog zahtjeva za podudarnošću HLA antigena i veće šanse za pronalazak podudarnog organa u velikoj populaciji darivatelja. To je posebno korisno za visokosenzibilizirane pacijente na dijalizi. Drugi se organi (jetra, srce, gušterača, pluća) uglavnom alociraju nacionalno (dakle, primateljima unutar zemlje iz koje je bio darivatelj), s time da neke osjetljive skupine pacijenata (hitne transplantacije, retransplantacije, pedijatrijski pacijenti) imaju mogućnost alokacije unutar čitavog Eurotransplanta. Isto tako, ako unutar zemlje iz koje je bio darivatelj nema podudarnog primatelja, takav se organ nudi u drugim zemljama članicama, a ako ni tamo nema podudarnog primatelja organ se nudi u drugim europskim zemljama.

Savjetodavni odbori imaju ključnu ulogu u organizacijskoj strukturi ET-a kad je u pitanju razvoj novih preporuka i politika u alokaciji organa. U ET-u postoje posebni savjetodavni odbori za transplantaciju bubrega, jetre i tankog crijeva, gušte-

Hrvatska je postala punopravna članica Eurotransplanta 2007. godine. Članstvo u Eurotransplantu za Hrvatsku je korisno zbog omogućavanja što bolje podudarnosti darivatelja i primatelja, kao i mogućnosti da se u kratkom vremenu pronađe odgovarajući organ u slučajevima akutnog zatajenja organa, za što je bitno veća vjerojatnost u velikoj populaciji potencijalnih darivatelja organa.

rače i torakalnih organa. Također postoje odbori za tipizaciju tkiva, eksplantacijski proces i etička pitanja. Svaki odbor ima članove iz svih zemalja članica te liječnike iz ET-a koji se redovito sastaju kako bi razmatrali nove spoznaje i promjene u svojim područjima u skladu s vrlo dinamičnim razvojem transplantacijske medicine. Stručnjaci iz različitih zemalja članica ET-a u savjetodavnim odborima diskutiraju o potrebama i transplantacijskim sustavima u drugim zemljama, a imaju priliku i iskazati želje i potrebe specifične za svoju zemlju. U slučajevima kada stručnjaci u pojedinom odboru zaključe da su potrebne promjene $u$ pojedinim postupcima u alokaciji organa, odbor izrađuje preporuke za odgovarajuću prilagodbu u procesu alokacije. Takve preporuke zatim razmatra skupština ET-a čiji su članovi predstavnici nacionalnih transplantacijskih društava. Ako skupština prihvati preporuke savjetodavnog odbora, preporuke se šalju nacionalnim vlastima koje provjeravaju jesu li u skladu s nacionalnim zakonodavstvom i ciljevima zdravstvene politike u pojedinoj zemlji članici. Nacionalna zdravstvena administracija odgovorna je i za eventualne izmjene u nacionalnom zakonodavstvu, kad je to potrebno. Tek nakon što nacionalna administracija pojedine zemlje članice odobri takve promjene u alokaciji, 
one se mogu implementirati u zemljama članicama ET-a $a^{1,2}$.

\section{REPUBLIKA HRVATSKA I EUROTRANSPLANT}

Početkom dvijetisućitih jedan od glavnih vanjskopolitičkih ciljeva Republike Hrvatske bio je ulazak u punopravno članstvo Europske unije. Tako je hrvatski zahtjev za punopravno članstvo podnesen 21. veljače 2003. godine, a službeni status kandidata za članstvo Hrvatska je dobila 18. lipnja 2004. godine. Otprilike u isto vrijeme, u prvoj polovici prvog desetljeća 21. stoljeća, jači razvoj transplantacijske medicine istaknut je kao jedan od strateških ciljeva hrvatske zdravstvene politike. U tom kontekstu kao jedan od ključnih koraka nametnulo se članstvo u Eurotransplantu, međunarodnoj organizaciji koja je okupljala zapadne razvijene zemlje i jamčila dobro strukturiran i transparentan sustav razmjene i alokacije organa. Kako je Republika Hrvatska relativno mala zemlja, a znajući za važnost dobre podudarnosti darivatelja i primatelja organa u postizanju dobrih ishoda u transplantaciji, bilo je logično da se Hrvatska priključi velikoj i učinkovitoj multinacionalnoj organizaciji, kako bi se hrvatskim primateljima osigurala dostupnost organa iz velike populacije potencijalnih darivatelja. Već u jesen 2005. godine ministar zdravstva Republike Hrvatske prof. dr. sc. Neven Ljubičić poslao je predsjedniku Eurotransplanta prof. dr. sc. Bruni Meiseru pismo $u$ kojem je izrazio želju Republike Hrvatske za suradnjom. Uskoro je uslijedio posjet predsjednika ET-a, Brune Meisera Hrvatskoj i već u svibnju 2006. godine potpisan je preliminarni ugovor o suradnji u razmjeni organa za hitne, visokosenzibilizirane i pedijatrijske pacijente. Samo dva mjeseca kasnije prvi pacijent kojem je trebala hitna transplantacija jetre stavljen je na listu čekanja ET-a i ubrzo mu je uspješno izvršena transplantacija. Nakon godine dana pridruženog članstva Republika Hrvatska je zadovoljila sve formalne uvjete za pristupanje i 26. svibnja 2007. godine, šest godina prije pristupanja Europskoj uniji, na svečanosti organiziranoj u Zagrebu i službeno je postala sedma punopravna članica ET-a ${ }^{3}$. Pristupanje Republike Hrvatske Eurotransplantu koincidiralo je sa značajnim porastom transplantacijske aktivnosti u Hrvatskoj prvenstveno kao posljedi- com značajnog porasta broja kadaveričnih darivatelja organa. Uz razvoj jedinstvenog hrvatskog organizacijskog modela darivanja i transplantacije organa, kao i svekoliko unapređenje sustava transplantacije organa, i članstvo u ET-u bilo je jedan od ključnih čimbenika koji su do 2010. godine i u sljedećim godinama doveli do svojevrsnog booma u donaciji i transplantaciji organa. Tako je Hrvatska po broju kadaveričnih darivatelja organa, kao i po broju transplantacija pojedinih solidnih organa na milijun stanovnika, izbila na vodeća mjesta u svijetu i tamo se uspješno održava sve do danas. Kao takva, Republika Hrvatska je već nekoliko godina najuspješnija članica ET-a po broju darovanih i transplantiranih kadaveričnih organa na milijun stanovnika (slika 2). Rezultati Republike Hrvatske prepoznati su u ET-u i dr. Mirela Bušić, nacionalni transplantacijski koordinator u Ministarstvu zdravstva je za zasluge u ovim uspjesima i uspješnu integraciju Republike Hrvatske u ET 2012. godine nagrađena nagradom Eurotransplanta.

Eurotransplant je odigrao (i još ima) važnu ulogu i u razvoju jedine transplantacije solidnog organa koja se u RH još ne vrši - transplantacije pluća. Naime, kroz ET je RH uspostavila suradnju s Allgemeines Krankenhaus (AKH) u Beču, pri čemu se hrvatskim pacijentima s terminalnim zatajenjem pluća transplantacije rade u Beču, a eksplantacijski timovi iz Beča i drugih centara u ET eksplantiraju pluća hrvatskih darivatelja. Također, u tijeku je edukacija hrvatskih timova koji bi uskoro trebali započeti s programom transplantacije pluća u KBC-u Zagreb u Hrvatskoj.

\section{ZAKLJUČAK}

Eurotransplant je međunarodna organizacija koja je tijekom posljednjih pedeset godina značajno pridonijela napretku transplantacijske medicine u zemljama članicama. Zajedničkim pristupom alokaciji organa i prekograničnom razmjenom organa omogućeno je da se unutar velike populacije potencijalnih darivatelja za svakog primatelja uvijek pokuša pronaći najpodudarniji mogući organ, zatim da pacijenti kojima je hitno potrebna transplantacija kao postupak koji im može spasiti život što prije dobiju organ, kao i da se dostupni organi iskoriste na najbolji način i s najboljim mogućim ishodi- 


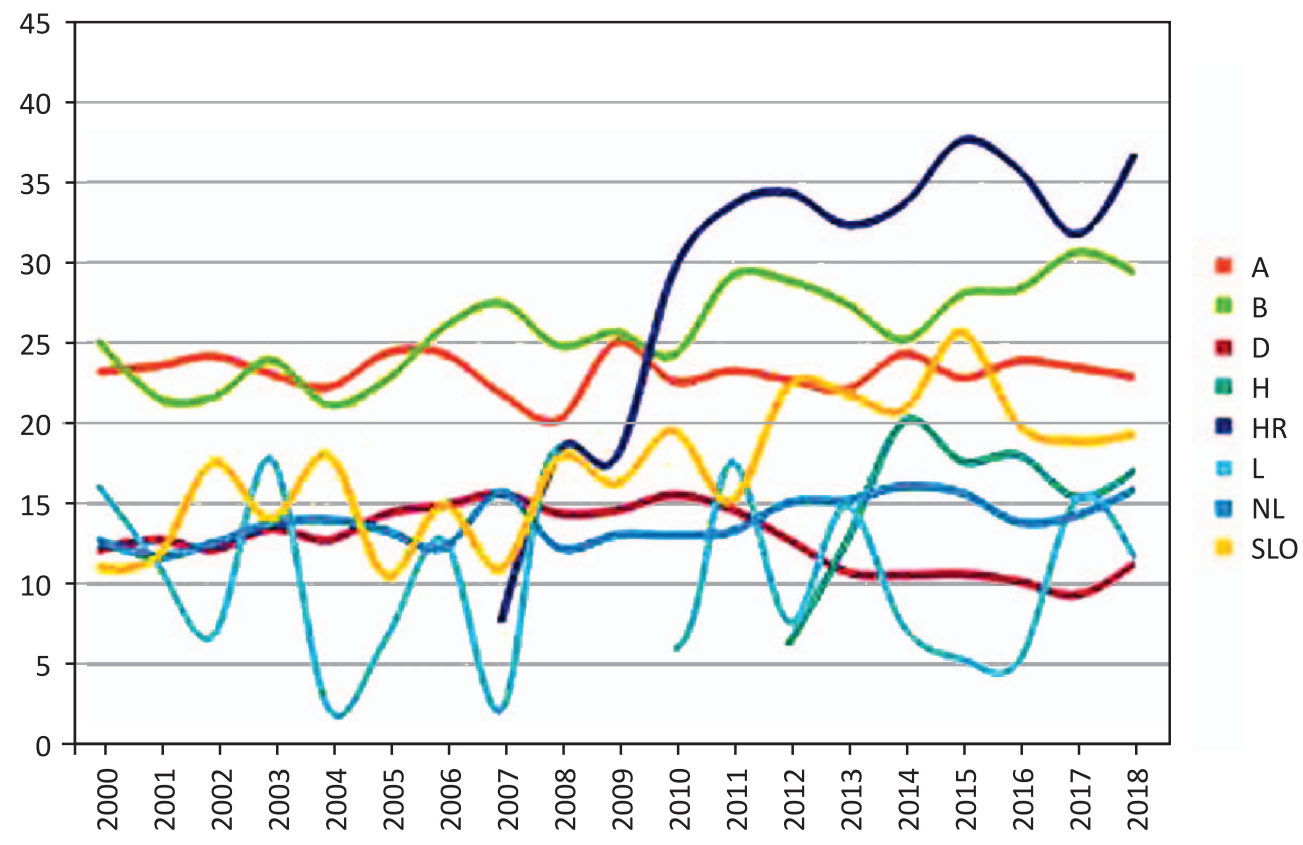

Slika 2. Broj kadaveričnih darivatelja na milijun stanovnika u zemljama članicama Eurotransplanta (Izvor: Godišnje izvješće Eurotransplanta za 2018. godinu, www. eurotransplant.org).

ma. Republika Hrvatska je kao relativno mlada i mala država dobro iskoristila prednosti pristupanja ovakvoj organizaciji koja počiva na čvrstoj strukturi i transparentnosti. Usporedno s pristupanjem Eurotransplantu, u Hrvatskoj je došlo do velikog porasta broja kadaveričnih darivatelja organa i broja učinjenih transplantacija, te je ona danas po tim parametrima najuspješnija članica ove organizacije.

Izjava o sukobu interesa: Autori izjavljuju da ne postoji sukob interesa.

\section{LITERATURA}

1. Eurotransplant [Internet]. Together on a life-saving mission - The world of Eurotransplant. [Cited 01 February 2020]. Available from: https://www.eurotransplant.org/ $\mathrm{cms} /$ index. php?page $=$ newsitems\&oid=458\&action=vie witem\&id=15682.

2. Eurotransplant [Internet]. Annuall Report 2018. [Cited 01 February 2020]. Available from: https://www.eurotransplant.org/cms/mediaobject.php?file=ET_Jaarverslag_20186.

3. Ministarstvo zdravstva. Nacionalni transplantacijski program. [Cited 01 February 2020]. Available from: https:// zdravstvo.gov.hr/nacionalni-transplantacijski-program/1528. 